\title{
JEAN GASTON DARBOUX.
}

JEAN Gaston DaRboUx, one of the most illustrious of our honorary members, was born* at Nîmes on the 13th of August, 1842, and died in Paris on the 23rd of February, 1917. His father died when the boy was. seven years old; his immediately succeeding years were sedulously directed by his mother, who had the intelligence and the outlook that are characteristic of so many French women. Seeing that the boy's disposition tended towards study rather than business, she made every effort to secure for him a steady, continuous education.

First at Nìmes, and later at Montpellier, he pursued his studies, with an obvious bent towards mathematics. At the age of nineteen he came out at the head of the list for admission into the Ecole Polytechnique, and the Ecole Normale Superieure in the section of Science. The choice of school rested with him; so he chose the École Normale. The selection was a surprise at the time; for it meant that the candidate elected for teaching, instead of the more honoured activities of public service as then estimated; and it had never previously been exercised in that sense. But the choice was applauded by Pasteur, the sub-director of the school ; later, it was followed as a precedent by Appell, Picard, and others; and, fifty years afterwards, it still appealed to the imagination of his colleagues.

At the École Normale, he spent three years as a student. He attended the lectures of Bertrand, thus beginning a friendship that suffered no break until the death of the older man; and other friendships then were formed with men whose names now are classics, Briot, Bouquet, Chasles, Serret. His main studies appear to have been in the range of geometry. His first original paper was concerned with orthogonal surfaces, and was presented to the Academy of Sciences by Serret in 1864. In that year he graduated, again at the head of the list. Pasteur, now the director of the scientific section of the school, had a post specially created for him, yielding him enough leisure for original work. The result appeared in his thesis, Sur les surfaces orthogonales, by which, in 1866, he obtained his doctor's degree.

For the next six years he was occupied in secondary teaching, which proved rather exacting. Still, he found time to pursue his researches in geometry; and he began to publish short memoirs on other subjects, such

\footnotetext{
* The writer of this notice is indebted, for many of the biographical facts, to the volume Éloges académiques et discours, published on the occasion of Darboux's jubilee, and to a monograph Gaston Darboux; by M. Ennest Lebon. [These pages were in type before the writer had seen the Notice historique, by M. Émile Picard, read at the meeting of the Academy of Sciences on 10th December, 1917.]
} 
as the singular solutions of ordinary differential equations of the first order, and the theory of partial equations of the second order.

One personal incident of this period may be recalled. At the outbreak of the Franco-Prussian War, in 1870, Sophus Lie was one of the foreign students attending Jordan's lectures in Paris. Being a Norwegian, he was allowed to remain if he wished. He determined on a long tramp to Italy. But he went no further than Fontainebleau. There he wandered among the woods and busied himself with his calculations and geometrical figures. He was soon arrested and imprisoned by military authorities, who saw spying and plans of fortresses in the names of mathematicians and in diagrams of complexes. After several unsuccessful attempts at communicating with French mathematicians, who were absent on the national defence, he got into relation with Darboux ; and Darboux's efforts won freedom for Lie.

In 1872, Darboux passed from secondary teaching to work of a University standard, returning in the first instance to the École Normale. From that date, his promotions were regular and rapid. After having filled intermediate chair's, he was appointed, in 1881, to the Professorship of Higher Geometry in the Faculty of Sciences at Paris, a chair originally created for Chasles in 1846. Not an unworthy successor of that illustrious geometrician even at the date of his appointment, he continued his researches and developed his teaching for some thirty years; and long before the end of that period he would, I think, have been acclaimed as the greatest living master of differential geometry.

In 1884 he was elected a member of the Academy of Sciences in the section of geometry. He was made Dean of the Faculty of Sciences in 1889 and held that office until 1903, when, on his resignation, he was succeeded by Appell. In 1900, on the death of Bertrand, he was appointed Perpetual Secretary of the Academy, on the side of the mathematical sciences. He discharged his varied duties with a zeal, a success, and a courtesy that were universally acknowledged; and he held this high and responsible office until his death.

$\mathrm{He}$ had entered the profession of teaching by entering the Ecole Normale in 1861. Fifty years afterwards there was a celebration of this event, in which mathematicians from all over the world took part.

He was a not infrequent visitor to England, mostly for important ceremonials or for meetings of international committees. Thus he was one of the leading members of the Central Committee of the International Association of Academies. At the Stokes Jubilee, in 1899, he was the representative of the University of Paris; as that University had the pride of age among all the bodies represented, Darboux had the pride of place. And at the funeral of Lord Kelvin in Westminster Abbey, in 1907, he came as the representative of the Institute of France. 
He spent his life within what may be called an academic round; and it obeyed the Horatian injunction

\section{Qualis ab incepto processerit, et sibi constet.}

As a teacher, an investigator, and an administrator in many fields, he had a full life. Academic honours, the most fitting recognition of such work, came to him in profusion. He was a foreign or an honorary member of more than thirty Academies and learned Societies. It is a satisfaction to note that our own Society was one of the very earliest to pay tribute to his genius ; he was made one of our honorary members as early as 1878 , and so was nearly the senior among them at the time of his death. He was elected a foreign member of the Royal Society in 1902, and, in 1916, was awarded the Sylvester medal. And the University of Cambridge in 1899 conferred upon him an honorary Doctorate of Science on the occasion of the Stokes Jubilee.

He had the reputation of being an ideal professor, alike in teachingr and in stimulus; in so far as his books and his memoirs give indication of professorial qualities, he certainly deserved his reputation. He was considered excellent as an administrator, alike in organisation and in development, and possessed "business capacity" which is not supposed to be the possession of all able mathematicians. The writer of this notice remembers well the easy strength with which Darboux presided over the meetings of the International Association of Academies in its first general assembly at Paris in 1901 ; yet there were some fiery members among the delegates. Time after time, in earlier years as a representative of the Faculty of Sciences, and in later years as a Perpetual Secretary of the Academy, it was his lot to deliver historical and other addresses, and to write commemorative notices of distinguished men of science. Darboux, in full measure, had the power of writing just appreciations, and, above all, he had that grace of style which is a very special possession of French writers.

Darboux was quite tall, of good presence, and (as he struck me) inclined to be thin. He wore pince-nez, and, at a distance, his face seemed to be a little severe; but when he recognised an acquaintance, the severity melted at once into the sunlight of a warm and friendly welcome. He had a quality of humour which revealed itself in addresses and in speeches, though not in his mathematical work; most mathematicians (Maxwell was an exception) will not allow a flavour of humour in their published work.

Darboux's original contributions to mathematical science covered a large field. In the later years of the last century, and in the earlier years of the present century, he would probably have been known best by his work in geometry, especially infinitesimal geometry. 'T'here his influence was supreme, through his mernoirs and books, and through the work of a 
succession of brilliant pupils inspired by him. But in his life he made valuable contributions to many other subjects : to analytical mechanics, celestial mechanics, and mathematical physics, to algebra and algebraical geometry, to several branches of the integral calculus and the theory of functions, and to parts of the theory of differential equations. In illustration of these statements, a few of his memoirs will be mentioned briefly.

Many of his early papers were concerned with applied mathematics; and their topics doubtless arose in connection with his duty to teach that subject at the Sorbonne in the early seventies. These were partly summarised in a set of notes which he added in an edition (1889) of Despeyrous's Cours de Mécanique, in his two-volume edition (1888, 1900) of Fourier's works, and in his edition (1888) of Lagrange's Mécanique Analytique.

In the integral calculus, two publications stand as of special importance. One of these is his monograph (1882) on Pfaff's Problem; the substance was communicated (1876) to Bertrand, who incorporated it in his lectures in the Collège de France. He dealt with the problem as belonging to the theory of equivaleut forms, and hardly at all as connected with the corresponding integral equations; and the derivation of his results was made to depend upon the significance of certain invariants of the differential form. The other memoir (1874), to which reference is made, was devoted to discontinuous functions; in it he resumed and extended Riemann's discussion of definite integrals. Much further progress in this last subject has been made in the last twenty years; but Darboux's contribution was a real development at the date of its publication.

In the region of differential equations, he made advances that were at once notable and useful. In the late sixties, much had been written round the singular solutions of ordinary equations of the first order; and not all of it was satisfactory. Cayley in 1872, and Darboux very early in 1873, working independently of one another, published some investigations, brief in extent, which have remained a stable foundation for the theory of those singular solutions. Their results have been greatly amplified; the publication was an epoch in the theory.

A much more extensive and impressive work was Darboux's crowned Mémoire sur les solutions singulières des équations aux dérivées partielles du memier ordre (1880). In its wide range and its novel results, and specially in its development of the theory of characteristics and its applications of contact transformations, it is little less than a treatise on the theory; and it holds a prominent place in the subject.

Partial equations of the first order can be regarded as integrable : that is to say, the difficulties which occur in constructing the integral are merely difficulties of manipulative analysis, such as quadratures and the integration of ordinary equations; they are below the domain of the theory of partial equations. But it is a vastly different matter when we have to deal 
with partial equations of the second order (and, as a natural consequence, of order higher than the second). There is a great array of literature dealing with some important individual equations of the second order, especially those which occur in mathematical physics; but methods of general integration are sadly lacking. The name of Mouge, of course, occurs at once; success with his method is met only for very particular types of equations, and the conditions for success have been formulated. The method of Ampère is more general as regards types of equations to which it can be applied effectively; but it is difficult, and most workers soon find themselves stranded when applying it to all but the simplest equations. Darboux tackled the problem from another side, dealing with equations that are integrable in a form that is free from what Amperre called "partial quadratures". The idea of Charpit, for equations of the first order with two independent variables (ultimately extended by Jacobi to equations of the first order with any number of independent variables), was to associate with a given equation of the first order an independent but consistent equation, also of that order. Darboux amplified the notion by associating with an equation of the second order in two independent variables an independent and consistent equation, it might be of the first order, or of the second order, or of a higher order; and his method will provide a consistent associable equation of finite order if the original equation is of the Ampère type. His method, without supplying the complete solution, which usually cannot be obtained in the finite terms so dear to those who "solve" equations, marks a real advance in the theory; and it has led to wider investigations since its publication in 1870 .

But, after all (and $I$ am not attempting an exhaustive record of Darboux's work), he probably was best known to the contemporary world of mathematicians by his classical treatise on infinitesimal and differential geometry-a subject in which he was a veritable pioneer. As already stated, his earliest paper was on orthogonal surfaces, published in 1864 ; it was only in 1910 that he issued the completed form of his investigations on the subject in the volume, Leçons sur les systèmes orthogonaux et les coordonneés curvilignes. Between those two dates, the mouumental treatise, Leçons sur la théorie générale des surfaces et les applications géométriques du calcul infinitésimal, appeared in four volumes, in 1887,* in 1889, in 1894, and in 1896 respectively. It is practically an encycloprdia of the subject, with a tremendous store of results, either new or newly developed; together with applications to and from all sorts of branches of mathematics, as varied as dynamics, soap-bubbles, partial differential equations, conformation, deformation, congruences, and cyclical systems. It is a great work, the achievement of a master.

* A second (and amplified) edition of the first volume appeared in 1914. 
Mention should a!so be made of an exceedingly interesting volume, Principes de géométrie analytique. It practically contains his lectures on principles, delivered from time to time through many years at the Ecole Normale and the Faculté des Sciences; it does not aim at being other than fairly elementary; and, in its union of analysis with what Poincaré called the "geometrical sense", it is characteristic of Darboux in his mental attitude towards geometry. It is probably the last work completed by him; for its preface bears a date only a few weeks earlier than that of his death.

Of his multifarious activities, only one other will find mention here. In 1870, he founded the Bulletin des sciences mathématiques et astronomiques. With a slight change of title in 1885, it has continued, to the great advantage alike of original papers and of reviews. He secured plenty of collaboration; Picard and J. Tannery were associated with him from the first. But the most prolific contributor must have been himself; he wrote over seventy articles in all, original papers, reviews of collected works and individual treatises and memoirs, indeed anything and everything that comes the way of an active editor.

If a mathematician's fame is to live, it must live on his enduring contributions to his science; it will hardly survive long from his teaching, and not at all from his administrative work, however useful. The judgment, as well as the admiration of his contemporaries, would predict that Darboux's original work will keep his fame fresh in long remembrance. 